\title{
Application of Combined BIM and 3D Point Cloud on Building Deconstruction
}

\author{
Xin Janet Ge* and Johnny Kwok Wai Wong \\ University of Technology Sydney, School of Built Environment, Australia
}

Submission: August 11,2017; Published: August 23, 2017

*Corresponding author: Xin Janet Ge, School of Built Environment, University of Technology Sydney, PO Box 123 Broadway, NSW 2007, Australia, Tel: 06129514 8074; Email: xinjanet.ge@uts.edu.au

Abstract

While building information modelling (BIM) has been extensively applied to the design and construction stages, there has been only limited use of BIM for demolition or reconstruction phase in minimizing and managing demolition waste. This paper proposes the use of combined BIM and 3D point cloud technology for collecting and documenting of building material information and formulating strategies of deconstruction waste management. The purpose is to develop a methodology for improving accuracy of building material information, including information of reusability and recyclability; and reduce the cost of energy and environmental impacts. A building deconstruction project in Sydney was adopted in this paper and found an estimated total of AUD\$1.5 million landfill levy can be saved based on the proposed methodology.

Keywords: BIM; 3D Point cloud; Building deconstruction; Sustainability; Waste management

\section{Introduction}

With the rapid development of infrastructure in many countries over the last two decades, the environmental impacts of construction and demolition (C\&D) activities has drawn much attention from both academic and industry. Effective C\&D waste management and practices have been requested to alleviate waste generation problem with the growing awareness of environmental sustainability [1,2]. Despite these escalating concerns, the issue of alleviating C\&D waste on site is still largely unresolved. For one reason, the economic performance of construction projects is still considered the foremost driver when it comes to the C\&D waste management, and the environmental performance of a development project is still considered a lower priority $[3,4]$. The shortage of efficient C\&D waste quantification tool, poor design and construction management are considered the culprits of C\&D wastage problem on-site [5].

While building information modeling (BIM) has been extensively applied to the design and construction stages, there has been only limited use of BIM for demolition or reconstruction phase in minimizing and managing demolition waste. In the last few years, an increasing number of studies have been conducted by academics. For example, Cheng \& Ma [6,7] used the BIM system to combine information for detailed waste estimation and planning which can be used to predict the number of truck delivery journeys and the amounts of statutory waste disposal charges. Hamidi et al. [8] demonstrated the application of a combined cost-benefit analysis and BIM tool for managing the demolition waste of a wooden framed residential building. Won et al. [9] developed a construction waste estimation system with the use of BIM-based design validation process to predict the amount of waste which might be generated due to design errors in the construction project. Won \& Cheng [10] proposed a timebased framework adopting BIM to quantify on-site waste by incorporating material information extracted from BIM models, project schedule, and waste factors for building materials developed by Chen et al. [11].

Despite these efforts, it has been argued that there is a lack of accurate information about the architectural, structural and facilities of existing buildings as the original design and drawings of these buildings might have changed or altered or not be found [12]. Also, most of the C\&D waste management researches has been focused on the waste which are generated in the construction stage (i.e. construction waste). In fact, the amount of waste generated in the demolition/deconstruction phase is larger than those in the construction phase [10]. So far, only a very limited number of studies were dealing with waste minimization and management in building deconstruction phase. Existing waste estimation tools are not accurate and convenient enough for the demolition contractor to manage the waste of a facility in an efficient way Hamidi et al. [8]. 


\section{Civil Engineering Research Journal}

Many qualification methods are based on manual waste estimation processes [5]. For example, AGC (2005) established a digital BIM visualizing tool to identify C\&D waste materials data, which allow the project team to develop material recycling plan before an actual demolition or renovation. Akbarnezhad et al. (2014) developed a BIM-based model for assessing the effects of various building deconstruction options in term of their economic costs and environmental benefits (i.e., minimization of carbon emission and energy consumption). Akinade et al. (2015 and 2016) adopted a mathematical modeling approach to develop BIM-based Deconstruct ability Assessment Score (BIM_ DAS) for measuring the level of building deconstruct ability during design stage and establishing a benchmark for effective deconstruction requirement.

For these reasons, this paper proposes the use of combined BIM and 3D point cloud technology for collecting and documenting of building material information and formulating strategies of deconstruction waste management. Different from BIM, which is a 3D-based framework showing all the building components and their relationships (Akbarnezhad et al. 2014), 3D point cloud collects building information through scanned images or photos in the form of point clouds, which can be converted them into 3D models ready for BIM [13]. This technology helps develop a methodology for improving accuracy of building material information, including information of reusability and recyclability. It also helps reduce the cost of energy and environmental impacts. A building deconstruction project in Sydney was adopted in this paper to illustrate the application of the proposed methodology.

The deconstructed building consisted of six levels of classrooms and offices including basement. The building came to the end of its life and the owner of the building considered appropriate deconstruction approach which can minimize the environmental impact and maximize the reusability of demolished building materials. The project team incorporated combined BIM and 3D point cloud technology in the deconstruction and waste management plans as the following steps. First, as-built drawings of original building structure and mechanical, electrical and plumbing (MEP) were obtained for the purpose of understanding the types of building material, their locations and quantities.

Sketches were obtained from on-site building survey when the original drawings were lost. In order to acquire accurate data capture and store a myriad of details about the interior of building, photos were taken and reconstructed using 3D point cloud technology to generate measurements of the interior spatial and material conditions (Figure 1) [14]. For the building exterior, drone was used to capture and analyze aerial data (Figure 2). Both 3D reconstruction and drone devices have provided dynamic visualization of the building and improved accuracy of the building information. Then, all information collected was integrated into the building information modeling (BIM).

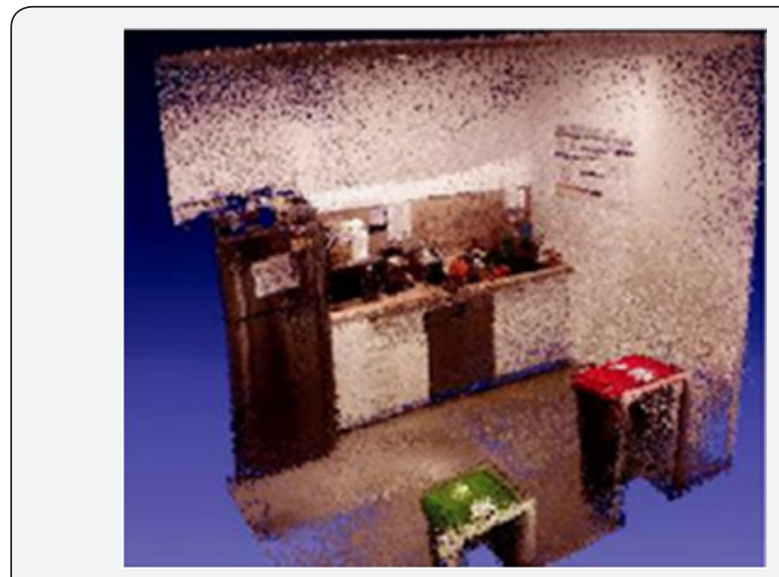

Figure 1: An example of reconstructed 3D Wang et al. [14].

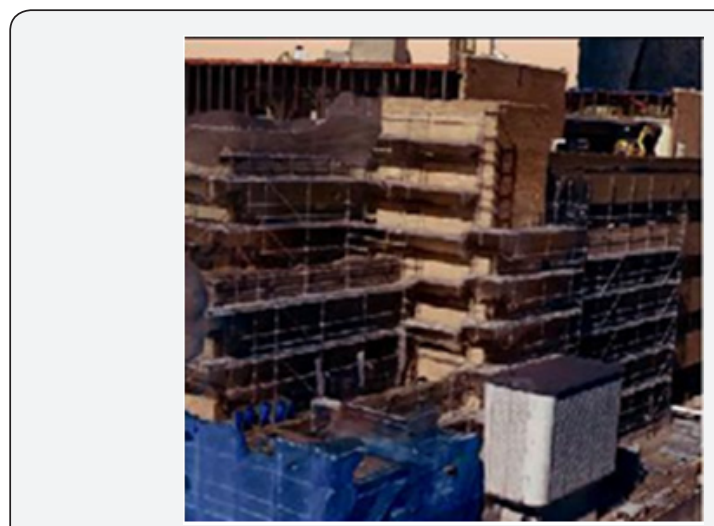

Figure 2: Building exterior data captured by drone.

At this stage, all information of the building component, quantities and as-built joint locations, etc. were identified and analyzed (i.e., what, where and how many) through BIM's quantity taking-offs function. The deconstruction cost, and the quantity of reusable and recyclable materials were then established. This combined tool provides accurate estimations of deconstruction materials and helps establish a timely waste management plan. An estimated total of AUD\$1.5 million landfill levy can be saved in this project as a result of the effective material reusability and recyclability planning.

\section{Conclusion}

In summary, the combined BIM and 3D point cloud improve not only the efficient of data collection and accuracy of the building information, but also enhance reusability and recyclability of building material. The productivity and economic benefits of BIM and 3D point cloud to the building industry are gradually acknowledged, such as cost reduction and control through the project life cycle Bryde, et al. 2013. Another benefit appears in the structured and semantically enriched 3D digital models of 


\section{Civil Engineering Research Journal}

buildings [13]. Despite of these achievements, high set-up costs of these digital technologies remains a hurdle to the industry, in particular for the small contractors. Also, there is a shortage of trained specialists for 3D reconstruction. To enhance a wider adoption of these technologies, it requires closer collaboration amongst public and private sectors, as well as continuing R\&D in this area.

\section{References}

1. Wong JKW, Zhou JX (2015) Enhancing environmental sustainability over building life cycles through green BIM: a review, Automation in Construction 57: 156-165.

2. Wu W, Yang H, Chew D, Hou Y, Li Q (2014) A real-time recording model of key indicators for energy consumption and carbon emissions of sustainable buildings. Sensors 14(5): 8465-8484.

3. Wang JY, Yuan HP, Kang XP, Lu WS (2010) Critical success factors on-site sorting of construction waste: a China study, Resources, Conservation and Recycling 54: 931-936.

4. Yuan $H$ (2012) A model for evaluating the social performance of construction waste management. Waste Manag 32(6): 1218-28.

5. Won J, Cheng JCP (2017) Identifying potential opportunities of building information modelling for construction and demolition waste management and minimization, Automation in Construction 79: 3-18.

6. Cheng JCP, Ma LYH (2012) A BIM-based system for demolition and renovation waste quantification and planning, Proceedings of the $14^{\text {th }}$ International Conference on Computing in Civil and Building Engineering, Moskow, Russia.

7. Cheng JCP, Ma LYH (2013) A BIM-based system for demolition and renovation waste estimation and planning, Waste Management 33(6): $1539-1551$.

8. Hamidi B, Bulbul T, Pearce A, Thabet W (2014) Potential application of BIM in cost - benefit analysis of demolition waste management.

9. Won J, Cheng JCP, Lee G (2016) Quantification of construction waste prevented by BIM-based design validation: case studies in Sough Korea, Waste Manag 49: 170-180.

10. Won J, Cheng JCP (2016) Time- based Construction Waste Management Planning Using Building Information Modelling (BIM).

11. Chen TY, Burnett J, Chau CK (2001) Analysis of embodied energy use in the residential building of Hong Kong. Energy 26: 323-340.

12. Chong HY, Lee CY, Wang X (2017) A mixed review of the adoption of Building Information Modelling (BIM) for sustainability. Journal of Cleaner Production 142: 4114-4126.

13. Hichri N, Stefani C, De Luca L, Veron P, Hamon G (2013) from point cloud to BIM: a survey of existing approaches. International Achieves of the Photogrammetry, International CIPA Symposium, Strasbourg, France, pp. 342-348.

14. Wang J, Huang SD, Zhao L, Ge XJ, He S, et al. (2017) High Quality 3D Reconstruction of Indoor Environments using RGB-D Sensors. The $12^{\text {th }}$ IEEE Conference on Industrial Electronics and Application (ICIEA 2017), Siem Reap Cambodia.

\section{Your next submission with Juniper Publishers will reach you the below assets}

